\title{
On the Value of Influence Activities for Capital Budgeting
}

\author{
Volker Laux* \\ Goethe University Frankfurt, Mertonstr. 17, 60054 Frankfurt, Germany
}

October 2005

\begin{abstract}
This paper shows that a capital budgeting process in which the division manager is required to engage in personally costly influence activities prior to a project approval has beneficial incentive effects: It provides the manager with incentives to acquire costly information about project prospects and helps to elicit the revelation of the acquired information. As a consequence, imposing influence costs on the manager can lead to improved capital allocations. The optimal level of influence costs, chosen by the firm, trades off ex ante incentives for information acquisition against efficient use of the acquired information ex post.

JEL Classifications: D82, G31

Keywords: Capital Budgeting; Influence Activities; Principal-Agent; Information Acquisition
\end{abstract}

*Tel.: +49 69798 23170; fax: +49 69798 22718. E-mail address: v.laux@em.uni-frankfurt.de. 


\section{Introduction}

Influence activities are ubiquitous in organizations. Managers spend considerable time and effort trying to influence decision makers. Examples include lobbying for larger capital budgets, more compensation, or promotion. Influence activities are typically viewed as wasteful and destructive. Most of the literature on this topic therefore discusses how changes in the organizational design can limit these activities (Milgrom, 1988; Milgrom and Roberts, 1988, 1990, 1992; Meyer et al., 1992). Specifically, recent research on internal capital markets stresses the negative consequences of influence activities. There is a widespread concern that rent seeking behavior leads to a misallocation of funds within organizations (Rajan et al., 2000; Scharfstein and Stein, 2000; Wulf, 2000)1 ${ }^{1}$.

This paper presents an alternative view of influence activities. I show that costly influence activities have beneficial effects (even when they are unproductive) because they can be used as an incentive tool. For this reason, influence activities can lead to an improved allocation of funds, rather than to a misallocation.

I model a firm with two parties, headquarters and a division manager. The manager's task is to gather information about the profitability of a potential project and to truthfully communicate this information to headquarters. There are two conflicts. First, the division manager is assumed to be an empire builder (Harris and Raviv, 1996; Stein, 1997; Baldenius, 2003). That is, he enjoys private benefits of control (power, reputation, fringe benefits) that increase with the size and profitability of his division. $^{2}$ Due to these benefits, the manager is biased in favor of the project (i.e., he

\footnotetext{
${ }^{1}$ See also Stein (2003) for an overview of this literature.

${ }^{2}$ Hennessy and Levy (2002) find substantial empirical evidence for empire building.
} 
tends to overinvest). Second, information acquisition is costly to the manager. Headquarters must therefore provide the manager with incentives to collect information about project profitability.

In this context, I show that influence activities have beneficial effects in terms of motivating information acquisition and eliciting truthful revelation of the acquired information. To see this, consider a capital budgeting process in which the manager is required to engage in personally costly influence activities to get the project approved. Influence activities come in different guises: for example, the manager has to prepare elaborate presentations in meetings or to submit detailed financial analyses. Given this procedure, the informed manager will "fight" for project approval only if the benefits of control associated with the project exceed the cost of influencing. Since empire benefits are linked to the success of the project, the manager's influence choice reveals hidden information about project prospects. In addition, this capital budgeting process provides the manager with some incentives to gather information about project profitability ex ante. This incentive arises from the manager's wish to base his influence decision on more accurate information. Intuitively, the manager prefers to become informed in order to avoid the risk of fighting for a project that involves only low benefits of control. However, the two control problems of motivating information acquisition and truthful communication interact. The optimal mechanism trades off the benefits of a high level of information acquisition with the benefits of an efficient use of the acquired information. Put differently, headquarters optimally induces an ex post inefficient investment policy in order to strengthen the manager's ex ante incentives to become informed.

The focus of this paper is on the incentive role of the capital budgeting process. For this reason, I rule out monetary incentives in the main part of the paper. However, 
I show in the extension section that influence activities remain beneficial if compensation is allowed. This follows because imposing costs of influence on the manager reduces the expected wage cost of providing the right incentives.

Apart from the influence activities literature mentioned above, the paper is related to several recent studies on capital budgeting. Harris and Raviv $(1996,1998)$ and Bernardo et al. (2001) consider models in which the division manager is costlessly informed about the profitability of the project and enjoys empire benefits. ${ }^{3}$ While Harris and Raviv $(1996,1998)$ analyze the incentive impact of internal auditing procedures, Bernardo et al. (2001) study the role of compensation in controlling the manager's empire-building preferences. The current paper contributes to this literature by emphasizing the role of influence activities in providing desirable incentives and by introducing endogenous information acquisition. Closest to my paper is Lambert (1986). He investigates how to motivate division managers to acquire costly information and to use this information efficiently. ${ }^{4}$ While Lambert (1986) focuses on managerial compensation to create incentives, I study the incentive role of influence activities and the capital budgeting process.

The remainder of the paper is organized as follows. Section 2 outlines the model. Section 3 presents the main results. Extensions of the basic model are discussed in Section 4 and Section 5 concludes.

\footnotetext{
${ }^{3}$ See also Harris et al. (1982), Antle and Eppen (1985), Arya et al. (1996) and Antle and
} Fellingham (1997) for models in which the manager prefers larger capital allocations to smaller ones.

${ }^{4}$ Other papers that model information acquisition endogenously are Demski and Sappington (1987), Prendergast (1993), Lewis and Sappington (1997), Cremer et al. (1998), and Stein (2002). 


\section{Model}

Consider a firm with two parties, headquarters and a division manager. Headquarters acts in the interest of owners and the division manager maximizes his own utility. The manager has no private wealth and can leave the firm at any time. All parties are risk neutral and only one period is considered. The risk-free rate of return and the manager's reservation utility are normalized to zero.

The division manager proposes a new project. To undertake the project, the division requires capital of $I$. Let $y, y \in\{0,1\}$, be an indicator variable that denotes whether the project is approved or rejected by headquarters. If $y=1$, the project is approved and the required capital amount $I$ is allocated to the division. The project generates gross profits of $x(\theta)$ that strictly increase with the quality of the project, denoted $\theta, \theta \in \Theta=[\underline{\theta}, \bar{\theta}]$. It is commonly known that $\theta$ follows a distribution function $F$ with positive density $f$. Assume there exists a cutoff value, $\theta^{z}$, with the properties $\theta^{z} \in(\underline{\theta}, \bar{\theta})$ and $x\left(\theta^{z}\right)-I=0$. Hence, the project has a positive net present value (NPV) if $\theta>\theta^{z}$ and a negative NPV if $\theta<\theta^{z}$. For ease of exposition, the expected NPV is assumed to be zero, $E_{\theta}[x(\theta)-I]=0$, absent information on true $\theta$.

Initially both headquarters and the manager are uninformed about $\theta$. The manager, but not headquarters, is able to gather this information at a cost. If the manager exerts effort $e, e \geq 0$, he privately observes project quality, $\theta$, with probability $p(e)$, $p(e) \in[0,1)$, and remains ignorant with probability $(1-p(e)) .{ }^{5}$ The probability function $p(e)$ is increasing and strictly concave, with $p(0)=0, p^{\prime}(0)=\infty$. The manager's cost of exerting effort $e$ is $e$.

\footnotetext{
${ }^{5}$ The manager does not receive a noisy signal of $\theta$. He either knowingly observes $\theta$ or knowingly remains with no better information than his prior.
} 
The manager is biased in favor of the project. When the project is undertaken, the manager enjoys private benefits of control, $b(\theta)$, with $b(\underline{\theta})=0$ and $b(\theta)>0$ for all $\theta>$ $\underline{\theta}$, that are strictly increasing in the quality of the project. ${ }^{6}$ This assumption captures the following (reasonable) preference restriction. The manager wishes to maximize the size of his empire and therefore tries to get the project approved regardless of true profitability (i.e., he tends to overinvest). But holding the size of his empire fixed, he prefers it to be profitable. Note that the private benefits of control assumption is not crucial for the main results of the paper (see Sections 4.1 and 4.2).

The manager can engage in influence activities. The level of influence exerted by the manager is denoted by $c, c \geq 0$. Fighting for funds is personally costly to the manager. Costs arise because the manager has to enthusiastically promote and sell his investment idea. For instance, the manager needs to sit in countless meetings, prepare elaborate presentations, submit financial analyses and written project proposals, or even may need to undercut competing proposals. In addition, opportunity costs of influence activities arise as the manager is kept from pursuing other rewarding tasks. Support for this assumption is provided by Ross (1986), who examined the capital budgeting processes of twelve large organizations. He observed that "If division management wanted to, they could increase this capital allocation by making a good case for it. But this would require a major effort..." I assume the manager's cost of exerting influence $c$ is $c$. The chosen level of influence activities is observable to headquarters. The manager's preferences are of the form $y b(\theta)-c-e$.

As a starting point, I assume influence activities do not directly affect the value

\footnotetext{
${ }^{6}$ This is a common assumption in the literature that deals with empire building. See, e.g., Harris and Raviv (1996, 1998), Bernardo et al. (2001), Stein (1997, 2002), and Baldenius (2003). Equivalently, one could assume that benefits of control increase with gross profits.
} 
of the firm. That is, influence activities are neither productive nor destructive and do not keep the manager from doing his regular job. I relax this assumption in Section 4.2 .

In order to focus on the incentive role of the capital budgeting process, I do not consider monetary incentives in the main part of the paper. In Section 4.1 and 4.2, I allow for managerial compensation and show that the beneficial effects of influence activities remain.

Headquarters announces the following capital budgeting process: the project is approved if and only if the manager engages in a certain level of influence activities, denoted $\widehat{c}$. In other words, there is a hurdle $\widehat{c}$ such that

$$
y=\left\{\begin{array}{l}
1 \text { for } c \geq \widehat{c}, \\
0 \text { for } c<\widehat{c} .
\end{array}\right.
$$

Given this approval rule, the manager either chooses $c=\widehat{c}$ or $c=0$. The Appendix contains a proof showing that this cutoff rule is indeed optimal.

The model has the following timing:

Stage 1: Headquarters announces the hurdle level $\widehat{c}$ for which the project will be approved.

Stage 2: The manager chooses the information acquisition effort level $e$.

Stage 3: Based on the information acquired, the manager decides wether to engage in influence activities $(c=\widehat{c})$ or forgo the project $(c=0)$. Given the manager's choice of $c$, the project is either approved or rejected. 


\section{Results}

This section is organized as follows. First, I analyze the manager's behavior given the capital budgeting process just described. Second, I discuss headquarters' optimal choice of $\widehat{c}$.

The Manager's Problem:

Consider first the manager's behavior in stage 3, i.e., after he has chosen effort $e$. At this point, the manager is either informed about $\theta$ (with probability $p(e)$ ) or is not informed (with probability $1-p(e)$ ).

If the manager is informed, he chooses to fight for funds $(c=\widehat{c})$ whenever the benefits associated with the project, $b(\theta)$, exceed the hurdle $\widehat{c}$. Hence, he chooses a threshold level, $\widehat{\theta}(\widehat{c})$, below which he will not engage in influence activities. (For notational convenience, the dependency of $\widehat{\theta}$ on $\widehat{c}$ is dropped hereafter.) Given $\widehat{c}$,

the manager's optimal threshold level satisfies $\widehat{c}=b(\widehat{\theta})$. The manager's choice of $c$ therefore reveals hidden information about $\theta$. If headquarters chooses the hurdle $\widehat{c}=b\left(\theta^{z}\right)$, the (ex post) optimal investment policy is implemented. In this case, the informed manager engages in influence activities if and only if the project's NPV is positive (which implies that only those projects are approved). However, as will be shown later, $\widehat{c}=b\left(\theta^{z}\right)$ is not the hurdle that maximizes headquarters' ex ante payoff.

If the manager remains uninformed, he engages in influence activities if the expected benefits associated with the project exceed the hurdle, i.e., if $E[b(\theta)] \geq \widehat{c}$.

Now consider the manager's optimal choice of $e$ in stage 2. The capital budgeting process provides the manager with incentives to gather information about $\theta$. This arises because the manager prefers to make informed decisions regarding whether to engage in costly influence activities. 
The value of information to the manager depends on his optimal strategy without information. It is necessary to distinguish between the two cases $\widehat{c}<E[b(\theta)]$ and $\widehat{c}>E[b(\theta)]$ in order to derive the manager's optimal choice of $e$.

Suppose first that $\widehat{c}<E[b(\theta)]$. In this case, the manager will fight for the project (i.e., he chooses $c=\widehat{c}$ ) when he does not know $\theta$. The manager's optimal choice of $e$ is the solution to the problem

$$
\max _{e} p(e)\left[\int_{\widehat{\theta}}^{\bar{\theta}}[b(\theta)-\widehat{c}] f(\theta) d \theta\right]+(1-p(e))[E[b(\theta)]-\widehat{c}]-e,
$$

where the first (second) term in square brackets is the a priori expected utility of the manager if he is informed (uninformed). ${ }^{7}$ The first-order condition on $e$ is

$$
p^{\prime}(e) \int_{\underline{\theta}}^{\widehat{\theta}}(\widehat{c}-b(\theta)) f(\theta) d \theta=1 .
$$

The manager prefers to obtain information in order to avoid the risk of fighting for a project that turns out to be of low quality. Specifically, the informed manager avoids a loss of $(\widehat{c}-b(\theta))$ for all $\theta \in[\underline{\theta}, \widehat{\theta})$. If the hurdle $\widehat{c}$ becomes greater, the potential loss from blindly fighting for the project increases, making it more attractive for the manager to gather information.

Lemma 1 If $\widehat{c}<E[b(\theta)]$, then $\frac{d e}{d \widehat{c}}>0$.

Suppose now that $\widehat{c}>E[b(\theta)]$. In this case, the manager forgoes the project (i.e., he chooses $c=0$ ) if he is uninformed about $\theta$. The manager solves

$$
\max _{e} p(e)\left[\int_{\widehat{\theta}}^{\bar{\theta}}[b(\theta)-\widehat{c}] f(\theta) d \theta\right]-e .
$$

The first-order condition on $e$ is

$$
p^{\prime}(e) \int_{\widehat{\theta}}^{\bar{\theta}}(b(\theta)-\widehat{c}) f(\theta) d \theta=1 .
$$

\footnotetext{
${ }^{7}$ Note that problems (1) and (3) are both well behaved.
} 
The benefit of being informed is that the informed manager enjoys a utility of $(b(\theta)-\widehat{c})$ for all $\theta \in[\widehat{\theta}, \bar{\theta}]$ whereas the uninformed manager would have foregone the project, receiving zero. If the hurdle $\widehat{c}$ increases, the benefit of information decreases and the manager exerts less effort $e$.

Lemma 2 If $\widehat{c}>E[b(\theta)]$, then $\frac{d e}{d \widehat{c}}<0$.

Lemma (1) and (2) lead to the next proposition.

Proposition 1 Maximum incentives for managerial information acquisition are provided if headquarters chooses the hurdle $\widehat{c}=E[b(\theta)]$.

The finding that incentives for information acquisition are non-monotonic in $\widehat{c}$ is related to the result in Khalil et al. (2005). This study analyzes the optimal cutoff under which the two tasks of planning and implementing a project should be integrated. The level of planning effort the agent chooses is non-monotonic in this cutoff level, implying that partial integration is optimal.

\section{Headquarters' Problem:}

Headquarters' choice of the optimal level of $\widehat{c}$ is the solution to the following problem:

$$
\max _{\widehat{c}} p(e) \int_{\widehat{\theta}}^{\bar{\theta}}(x(\theta)-I) f(\theta) d \theta
$$

subject to

$$
\widehat{\theta}=b^{-1}(\widehat{c}),
$$

(2) for $\widehat{c} \leq E[b(\theta)]$,

(4) for $\widehat{c}>E[b(\theta)]$. 
Constraint (6) captures the manager's optimal choice of the threshold level. Constraints (7) and (8) are the information acquisition incentive constraints. The manager's participation constraint is slack and hence is omitted. It is slack because the manager will only gather information and lobby for funds if the private benefits associated with the project compensate him for his efforts. ${ }^{8}$

Headquarters pursues two goals: It wants to motivate the manager to gather information and to make a good influence (investment) decision, given the information acquired.

As shown in Proposition 1, the manager's incentive to gather information is strongest if headquarters chooses the hurdle $\widehat{c}=E[b(\theta)]$. However, once the manager has observed $\theta$, the ex post optimal hurdle is $\widehat{c}=b\left(\theta^{z}\right)$. This hurdle ensures that the informed manager engages in influence activities if and only if the project has a positive NPV. ${ }^{9}$ Obviously, these two control problems interact whenever $E[b(\theta)] \neq b\left(\theta^{z}\right)$. Headquarters has to trade off the benefits of a high level of information acquisition with the benefits of an efficient use of the acquired information. This trade off leads to the next proposition.

Proposition 2 Let $\widehat{\theta}^{*}$ be the manager's threshold and $\widehat{c}^{*}$ be the hurdle level in the optimal solution.

$$
\text { If } b\left(\theta^{z}\right)=E[b(\theta)] \text {, then } \widehat{\theta}^{*}=\theta^{z} \text { and } \widehat{c}^{*}=b\left(\theta^{z}\right) .
$$

\footnotetext{
${ }^{8}$ This implies that imposing influence activities on the manager does not increase the firm's wage bill. In fact, as will be shown in Section 4.1, influence activities can be used to reduce the expected wage cost.

${ }^{9}$ Note that headquarters does not have to worry about the manager's influence decision if he is uninformed. This is due to the assumption that the project's expected NPV is zero. However, the results remain to hold even without this simplifying assumption.
} 


$$
\begin{aligned}
& \text { If } b\left(\theta^{z}\right)<E[b(\theta)] \text {, then } \widehat{\theta}^{*}>\theta^{z} \text { and } \widehat{c}^{*} \in\left(b\left(\theta^{z}\right), E[b(\theta)]\right] \text {. } \\
& \text { If } b\left(\theta^{z}\right)>E[b(\theta)] \text {, then } \widehat{\theta}^{*}<\theta^{z} \text { and } \widehat{c}^{*} \in\left[E\left[b(\theta), b\left(\theta^{z}\right)\right)\right. \text {. }
\end{aligned}
$$

Proof: See the appendix.

If $b\left(\theta^{z}\right)=E[b(\theta)]$, there is no interaction between the two control problems. The hurdle that maximizes incentives for information acquisition also makes sure that the acquired information is used efficiently ex post.

If $b\left(\theta^{z}\right)<E[b(\theta)]$, the optimal hurdle is such that the informed manager forgoes some positive NPV projects, i.e., $\widehat{\theta}^{*}>\theta^{z}$. To see this, suppose headquarters selects the hurdle $\widehat{c}=b\left(\theta^{z}\right)$. In this case, the ex post efficient investment policy is implemented once the manager is informed. The drawback of this hurdle level, however, is that the manager has relatively weak incentives to become informed ex ante. When the hurdle is increased, project approval becomes more costly to the manager, making it less attractive for him to go after the project uninformed. An increase of $\widehat{c}$ therefore improves incentives for information acquisition, but at the cost of ex post underinvestment. Underinvestment arises because a larger influence cost renders some positive NPV projects unattractive for the manager. The optimal hurdle therefore balances the ex ante benefit of a strong incentive for information acquisition against the ex post cost of underinvestment.

On the other hand, if $b\left(\theta^{z}\right)>E[b(\theta)]$, headquarters reduces the hurdle below $b\left(\theta^{z}\right)$ to improve incentives for information acquisition. Now, this comes at the cost of overinvestment. Hence, in this case, the ex ante benefit of information acquisition is balanced against the ex post cost of overinvestment. 


\section{Extensions}

\subsection{Monetary Incentives}

In the agency literature, incentives are usually provided by means of compensation contracts. It is therefore important to analyze the incentive role of influence activities in addition to managerial compensation.

The objective of this section is twofold. First, I want to show that there is a role for influence activities in addition to incentive pay; that is, influence activities remain part of the optimal capital budgeting process when compensation is allowed. Second, I demonstrate that private benefits of control are not a crucial ingredient to obtain the result that influence activities have beneficial effects.

To see this, consider a simplified setting with two possible project qualities, $\theta \in$ $\left\{\theta_{L}, \theta_{H}\right\}$ with $\theta_{H}>\theta_{L}$, and a binary effort choice, $e \in\{k, 0\}$. As before the NPV of the project is determined by $x(\theta)-I$. Headquarter's goal is to maximizes the expected value of $(x-I) y$ less the manager's compensation, specified below. Assume the project's NPV is positive only if $\theta=\theta_{H}$, that is, $x\left(\theta_{L}\right)-I<0$ and $x\left(\theta_{H}\right)-I>0$. The optimal investment policy is therefore to implement the project $(y=1)$ if $\theta=\theta_{H}$ and to reject it $(y=0)$ otherwise. If the manager chooses effort $e=k(e=0)$, he uncovers $\theta$ with probability $1(0)$. The private cost of effort $e$ is again $e$. The ex ante probability that $\theta=\theta_{H}$ is commonly known to be $q, q \in(0,1)$. Assume it is worthwhile for headquarters to provide the manager with incentives to learn $\theta$. Let $w_{H}$ and $w_{L}$ be the payments to the manager if the project is undertaken and the outcome is $x=x\left(\theta_{H}\right)$ and $x=x\left(\theta_{L}\right)$, respectively. Let $w_{0}$ be the pay if the project is

rejected. Finally, assume the manager does not enjoy any private benefits of control, i.e., $b(\theta)=0$ for all $\theta \in \Theta$. 
Headquarters' problem is

$$
\max _{w_{H}, w_{L}, w_{0}, c} q\left(x\left(\theta_{H}\right)-I\right)-q w_{H}-(1-q) w_{0}
$$

subject to

$$
\begin{aligned}
q\left(w_{H}-\widehat{c}\right)+(1-q) w_{0}-k & \geq q w_{H}+(1-q) w_{L}-\widehat{c}, \\
q\left(w_{H}-\widehat{c}\right)+(1-q) w_{0}-k & \geq w_{0} \\
q\left(w_{H}-\widehat{c}\right)+(1-q) w_{0}-k & \geq 0 \\
w_{H}-\widehat{c} & \geq w_{0} \geq w_{L}-\widehat{c} \\
w_{H}, w_{L}, w_{0} & \geq 0 .
\end{aligned}
$$

The first two constraints ensure that the manager prefers to gather information instead of always fighting for the project uninformed (constraint 9) or always forgoing the project uninformed (constraint 10). Constraint (11) is the participation constraint, which is slack given (10) and (13). Constraint (12) ensures that the manager chooses to engage in influence activities if and only if he observes $\theta=\theta_{H}$. This constraint is slack given (9) and (10). The last constraint requires payments to be nonnegative (limited liability).

Since all parties are risk neutral, it is optimal to set the pay $w_{L}$ as low as possible, i.e., $w_{L}=0$. Rearranging (9) and (10) yields

$$
\begin{aligned}
\widehat{c}+w_{0} & \geq \frac{k}{1-q}, \\
w_{H} & \geq \frac{k}{q}+\widehat{c}+w_{0} .
\end{aligned}
$$

In the optimal solution, both incentive constraints are binding. To see this note that the expected wage cost could be lowered if one of the constraints was slack.

The pay $w_{0}$ and influence cost $\widehat{c}$ are perfect substitutes in the two incentive constraints. Suppose for a second that the hurdle is zero, i.e., $\widehat{c}=0$. In this case, the 
optimal transfers are $w_{H}=\frac{k}{q(1-q)}, w_{0}=\frac{k}{1-q}, w_{L}=0$. Note that the manager receives a reward for not proposing the project, $w_{0}=\frac{k}{1-q}$. This reward plays an important incentive role because it keeps the manager from always proposing the project without having acquired information. Due to the limited liability assumption, the wage contract provides the manager with a rent of $\frac{k}{1-q}$.

Using this contract as a starting point, headquarters can increase the hurdle $\widehat{c}$ and by the same amount reduce the reward $w_{0}$ without altering incentives and without violating the participation constraint (until $w_{0}$ reaches zero). In other words, headquarters can simultaneously impose influence activities on the manager and reduce his expected compensation. This is a surprising result. After all, one would expect that the manager must be compensated for the increased burden of influence activities.

There are two reasons for this result. First, the rent the manager earns can be used as a compensation for the influence cost. This is why the participation constraint is not violated. Second, the personal cost of influence activities deters the manager from proposing the project uninformed. This reduces the need to use the pay $w_{0}$ for incentive provision, limiting the cost of the incentive contract.

The optimal contract is such that the expected incentive compensation is as low as possible. This is the case for $w_{H}=\frac{k}{q(1-q)}, w_{L}=w_{0}=0$ and $\widehat{c}=\frac{k}{1-q}$. The next proposition summarizes this result.

Proposition 3 Influence activities can be used to limit contracting costs and are part of the optimal capital budgeting process.

\subsection{Productive Influence Activities}

Earlier studies on influence activities assume that these activities are directly valuedestroying. In the setting of the current paper, it does not seem plausible to make 
this assumption. Headquarters has the authority to determine the capital budgeting process and, therefore, will rather induce productive influence activities. To give an example assume that projects require managerial input to be implemented. In this case, headquarters announces to approve a project proposed by the division manager only if the manager is willing to implement it (i.e., the manager is required to put his effort where his mouth is). Similar to the influence cost, the cost of implementing the project provides the manager with incentives for information acquisition. The manager wishes to obtain information in order to avoid wasting energy for implementing a project that fails anyway due to it's low quality. The implementation task can be interpreted as an influence activity since the manager's willingness to stick with his project convinces headquarters to approve it.

Consider again the setting discussed in Section 4.1. But assume now that the project's gross profits do not only depend on the project quality, $\theta$, but on the implementation effort, $c$, delivered by the manager. In particular, the production function has the form $x=\theta g(c)$ with $g^{\prime}(c)>0, g^{\prime \prime}(c)<0, g(0)=0$. For simplicity assume $\theta_{L}=0$ and $\theta_{H}=1$. Let $\widehat{x}=g(\widehat{c})$ be the target outcome the manager is asked to deliver if the project is undertaken. In other words, the manager is supposed to devote implementation effort $c=\widehat{c}$ to the project if he proposes it. Let $w_{H}$ and $w_{L}$ be the payments if $x \geq \widehat{x}$ and $x<\widehat{x}$, respectively, and $w_{0}$ be the payment if the project is not undertaken. In this setting, the information acquisition constraints are again given by (9) and (10). As before, $\widehat{c}$ and $w_{0}$ are substitutes in providing incentives. Hence, in the optimal solution, $\widehat{c} \geq \frac{k}{1-q}$ and $w_{0}=0$ must hold $\left(\widehat{c}\right.$ can now exceed $\frac{k}{1-q}$ because the implementation effort is productive). More precisely, the optimal level is $\widehat{c}=\max \left[\frac{k}{1-q}, c^{\#}\right]$ where $c^{\#}$ satisfies $g^{\prime}\left(c^{\#}\right)=1$. The optimal transfers are $w_{H}=\widehat{c}+\frac{k}{q}$ and $w_{L}=w_{0}=0$. 


\section{Conclusion}

This paper presents a positive view of influence activities. I find that the optimal capital budgeting process requires the division manager to engage in influence activities prior to a project approval. This procedure has beneficial effects in terms of motivating information acquisition and eliciting revelation of the acquired information. The positive incentive effects of influence activities offer an economic rationale for observed capital budgeting processes in firms.

The paper also discusses the incentive role of influence activities in addition to managerial compensation. Since influence activities create desirable incentives, headquarters can use these activities to ease the pressure on incentive pay. Put differently, a properly designed capital budgeting process can reduce the expected wage cost of providing incentives.

Influence activities might come in different guises. For instance, the task of implementing a project can be interpreted as an influence activity. The cost of implementing the project provides the manager with incentives for information acquisition because he wishes to avoid wasting effort for a project that fails anyway due to it's

low quality. Hence, the manager's willingness to stick with his project convinces headquarters to approve it. 


\section{Acknowledgements}

I wish to thank two anonymous referees, Stan Baiman, Tim Baldenius, Patrick Bolton, John Christensen, Ron Dye, Ralf Ewert, Frank Gigler, Bjorn Jorgensen, Chandra Kanodia, Mike Kirschenheiter, Rick Lambert, Christian Laux, Helmut Laux, Christian Leuz, Nahum Melumad, Sri Sridharan, Elu von Thadden, Alfred Wagenhofer, and seminar participants at Columbia University, Wharton School, London Business School, University of Minnesota, Northwestern University, and conference participants at the 2002 Carnegie Mellon Accounting Conference, the 2002 German Economic Association (Verein für Socialpolitik) Annual Meeting, the 2002 European Finance Association Annual Meeting, and the 2001 European Accounting Association PWC Doctoral Colloquium for their helpful comments. The paper was revised while I was visiting Columbia University which I thank for its hospitality. I also gratefully acknowledge financial support from KPMG.

\section{Appendix}

\section{The Capital Budgeting Rule}

It is shown that the cutoff rule described in Section 2 is optimal in the set of deterministic schemes. Consider a revelation mechanism where the manager is asked to send a report $\theta^{r} \in R$ about project profitability. Since it is possible that the manager is uninformed, the communication space is $R=\Theta \cup \theta^{o}$ where $\theta^{o}$ stands for no information. Headquarters responds according to a prespecified scheme $\left\langle c\left(\theta^{r}\right), y\left(\theta^{r}\right)\right\rangle$ where $c\left(\theta^{r}\right)$ is the level of influence the manager has to exert and $y\left(\theta^{r}\right)$ is the approval decision given the report $\theta^{r}$.

Any contract can implement no more than two different levels of influence. For any two reports, $\theta_{1}^{r}$ and $\theta_{2}^{r}$, the optimal contract must be such that $c\left(\theta_{1}^{r}\right)=c\left(\theta_{2}^{r}\right)$ if $y\left(\theta_{1}^{r}\right)=y\left(\theta_{2}^{r}\right)$. If, for example, $c\left(\theta_{1}^{r}\right)<c\left(\theta_{2}^{r}\right)$ and $y\left(\theta_{1}^{r}\right)=y\left(\theta_{2}^{r}\right)$, the manager will send 
the message $\theta_{1}$ when he knows $\theta_{2}$ is true. As the investment choice is binary, there are at most two different levels of influence activities. Moreover, $c\left(\theta^{r}\right)=0$ must hold if $y\left(\theta^{r}\right)=0$ : the manager will not engage in influence activities when this results in a project rejection. Thus, for all reports for which the project is rejected the required level of influence is $c=0$ and for all reports for which the project is approved the required level of influence is a constant $c=\widehat{c}$. By sending a report $\theta^{r}$, the manager therefore chooses between the two allocations $\langle y=0, c=0\rangle$ and $\langle y=1, c=\widehat{c}\rangle$.

The optimal mechanism involves a cutoff $\widehat{\theta}$ such that $y=0$ if $\theta^{r} \in[\underline{\theta}, \widehat{\theta})$ and $y=1$ if $\theta^{r} \in[\widehat{\theta}, \bar{\theta}]$. This follows because if $y\left(\theta_{1}\right)=1$, then $y\left(\theta_{2}\right)=1$ for all $\theta_{2}>\theta_{1}$. Suppose to the contrary that $y\left(\theta_{1}\right)=1, y\left(\theta_{2}\right)=0$ and $\theta_{2}>\theta_{1}$. Incentive compatibility requires that $b\left(\theta_{1}\right)-\widehat{c} \geq 0$ and $0 \geq b\left(\theta_{2}\right)-\widehat{c}$. The first (second) inequality makes sure that the manager truthfully reports $\theta_{1}\left(\theta_{2}\right)$ instead of $\theta_{2}\left(\theta_{1}\right)$. If the first inequality is satisfied, then the second is violated and vice versa, since $\theta_{2}>\theta_{1}$.

There is no value to communication. Instead of sending a report $\theta^{r}$ the manager can directly choose the level of influence $c$. Construct a new contract (indicated by superscript $o$ ) based on no communication: $y^{o}(c)=y\left(c, \theta^{r}\right)$ for any $\theta^{r}$ such that $c\left(\theta^{r}\right)=c$. The no communication scheme is performance equivalent to the communication scheme.

\section{Proof of Proposition 2}

Suppose that in the optimal solution $\widehat{c}<E[b(\theta)]$. Letting $\lambda$ and $\mu$ denote the

Lagrangian multipliers on constraints (6) and (2), $\widehat{\theta}, \widehat{c}$ and $e$ must satisfy the following first-order conditions

$$
\begin{gathered}
-p(e)(x(\widehat{\theta})-I) f(\widehat{\theta})-\lambda b^{\prime}(\widehat{\theta})+\mu p^{\prime}(e) \underbrace{(\widehat{c}-b(\widehat{\theta}))}_{=0} f(\widehat{\theta})=0, \\
\lambda+\mu p^{\prime}(e) F(\widehat{\theta})=0
\end{gathered}
$$




$$
p^{\prime}(e) \int_{\widehat{\theta}}^{\bar{\theta}}(x(\theta)-I) f(\theta) d \theta+\mu p^{\prime \prime}(e) \int_{\underline{\theta}}^{\widehat{\theta}}(\widehat{c}-b(\theta)) f(\theta) d \theta=0 .
$$

It is easy to check that $\lambda<0$, which implies that in the optimal solution $\widehat{\theta}>\theta^{z}$. Since $\widehat{c}<E[b(\theta)]$ implies $b(\widehat{\theta})<E[b(\theta)]$ and $\widehat{\theta}>\theta^{z}$ implies $b(\widehat{\theta})>b\left(\theta^{z}\right)$, it must be that $b\left(\theta^{z}\right)<E[b(\theta)]$.

In a similar way, it can be shown that if in the optimal solution $\widehat{c}>E[b(\theta)]$, then $\widehat{\theta}<\theta^{z}$. Since $\widehat{c}>E[b(\theta)]$ implies $b(\widehat{\theta})>E[b(\theta)]$ and $\widehat{\theta}<\theta^{z}$ implies $b(\widehat{\theta})<b\left(\theta^{z}\right)$, it must be that $b\left(\theta^{z}\right)>E[b(\theta)]$.

\section{References}

[1] Antle, R., Eppen, G.D., 1985. Capital Rationing and Organizational Slack in Capital Budgeting. Management Science 31, 163-174.

[2] Antle, R., Fellingham, J., 1997. Models of Capital Investments with Private Information and Incentives: A Selective Review. Journal of Business Finance \& Accounting 24, 887-908.

[3] Arya, A., Glover, J., Young, R.A., 1996. Capital Budgeting in a Multidivisional Firm. Journal of Accounting, Auditing \& Finance, 519-533.

[4] Baldenius, T., 2003. Delegated Investment Decisions and Private Benefits of Control. The Accounting Review 78, 909-930.

[5] Bernardo, A.E., Cai, H., Luo, J., 2001. Capital Budgeting and Compensation with Asymmetric Information and Moral Hazard. Journal of Financial Economics $61,311-344$. 
[6] Cremer, J., Khalil, F., Rochet, J.-C., 1998. Contracts and Productive Information Gathering. Games and Economic Behavior 25, 174-193.

[7] Demski, J.S., Sappington, D.E., 1987. Delegated Expertise. Journal of Accounting Research 25, 68-89.

[8] Harris, M., Kriebel, C.H., Raviv, A., 1982. Asymmetric Information, Incentives and Intrafirm Resource Allocation. Management Science 28, 604-620.

[9] Harris, M., Raviv, A., 1996. The Capital Budgeting Process: Incentives and Information. Journal of Finance 51, 1139-1173.

[10] Harris, M., Raviv, A., 1998. Capital Budgeting and Delegation. Journal of Financial Economics 50, 259-289.

[11] Hennessy, C., Levy, A., 2002. A Unified Model of Distorted Investment: Theory and Evidence. Working Paper, U. C. Berkeley.

[12] Khalil, F., Kim, D., Shin, D., 2005. Optimal Task Design: To Integrate or Separate Planning and Implementation. Journal of Economics and Management Strategy, forthcoming.

[13] Lambert, R.A., 1986. Executive Effort and Selection of Risky Projects. Rand Journal of Economics 17, 77-88.

[14] Meyer, M., Milgrom, P., Roberts, J., 1992. Organizational Prospects, Influence Costs, and Ownership Changes. Journal of Economics and Management Strategy $1,9-35$.

[15] Milgrom, P., 1988. Employment Contracts, Influence Activities and Efficient Organization Design. Journal of Political Economy 96, 42-60. 
[16] Milgrom, P., Roberts, J., 1988. An Economic Approach to Influence Activities in Organizations. American Journal of Sociology 94 (Supplement), 154-179.

[17] Milgrom, P., Roberts, J., 1990. Bargaining Costs, Influence Costs, and the Organization of Economic Activity. In: Alt, J., Shepsle, K. (Eds.), Perspectives on Positive Political Economy. Cambridge, UK: Cambridge University Press, 57-89.

[18] Milgrom, P., Roberts, J., 1992. Economics, Organization \& Management. Prentice-Hall, Englewood Cliffs, New Jersey.

[19] Prendergast, C., 1993. A Theory of "Yes Men". American Economic Review 83, $757-770$.

[20] Rajan, R., Servaes, H., Zingales, L., 2000. The Cost of Diversity: The Diversification Discount and Inefficient Investment. Journal of Finance 55, 35-80.

[21] Ross, M., 1986. Capital Budgeting Practices of Twelve Large Manufacturers. Financial Management 15, 15-22.

[22] Scharfstein, D.S., Stein, J.C., 2000. The Dark Side of Internal Capital Markets: Divisional Rent-Seeking and Inefficient Investment. Journal of Finance 55, 25372564 .

[23] Stein, J.C., 1997. Internal Capital Markets and the Competition for Corporate Resources. Journal of Finance 52, 111-133.

[24] Stein, J.C., 2002. Information Production and Capital Allocation: Decentralized vs. Hierarchical Firms. Journal of Finance 57, 1891-1921. 
[25] Stein, J.C., 2003. Agency, Information and Corporate Investment. In: Constantinides, G.M., Harris, M., Stulz, R. (Eds.), Handbook of the Economics of Finance. Elsevier Science B.V., 109-163.

[26] Wulf, J., 2000. Influence and Inefficiency in the Internal Capital Market: Theory and Evidence. Working Paper, Wharton School. 